\title{
ASSOCIATION OF OBESITY WITH PERIODONTITIS, TOOTH LOSS AND ORAL HYGIENE IN NON-SMOKING ADULTS
}

\author{
Jelena Prpić1, Davor Kuiš¹, Irena Glažar', Sonja Pezelj Ribarić ${ }^{1}$ \\ ${ }^{1}$ Department of Oral Medicine and Periodontology, School of Dentistry, Medical Faculty, University of Rijeka, Rijeka, Croatia
}

\section{SUMMARY}

Background: Periodontitis was found to be significantly related to obesity as well as the number of missing teeth and oral hygiene. However, the studies addressing these relationships often included smokers and diabetics, and none was performed in Eastern European patients. The aim of this cross-sectional study was to investigate associations between obesity and periodontitis, oral hygiene, and tooth loss in a sample of non-smoking Croatian subjects aged $31-75$ years.

Methods: A total of 320 patients were recruited by convenient sampling at the Dental Clinic, Clinical Hospital Centre in Rijeka, Croatia. Periodontal examination and data on tooth loss were completed in 292 subjects and each participant completed a structured written questionnaire with questions regarding oral hygiene, education, height, and weight. Periodontitis was categorized as early, moderate and advanced. In multiple regression analysis, periodontitis was used as predictor variable, and BMI, oral hygiene, tooth loss, and education level were used as dependent variables.

Results: Use of interdental brushes/flossing and number of missing teeth correlated significantly with BMI, but the same could not be proven for periodontitis and frequency of tooth brushing. However, logistic regression proved that the subset of obese, poorly educated women aged 36-55 years were 5-6 times more likely to develop severe forms of periodontal disease.

Conclusions: Obesity was associated with tooth loss, oral hygiene, and education level in the investigated group. BMI could not be correlated with severity of periodontal disease, except in poorly educated women aged $36-55$ years.

Key words: Body Mass Index - BMI, dental devices, home care, obesity, periodontitis, tooth loss

Address for correspondence: J. Prpić, Strossmayerova 3, 51000 Rijeka, Croatia. E-mail: jelena.horvat@medri.hr

\section{INTRODUCTION}

According to the World Health Organization (WHO), overweight and obesity are defined as abnormal or excessive fat accumulation that may impair health. The fundamental cause of obesity and overweight is an energy imbalance between calories consumed on one hand, and calories expended on the other hand. The WHO's latest projections indicate that globally in 2005 approximately 1.6 billion adults (aged $15+$ ) were overweight and at least 400 million adults were obese. WHO further projects that by 2015 , approximately 2.3 billion adults will be overweight and more than 700 million will be obese (1).

Overweight and obesity are regarded as important risk factors for various diseases: type 2 diabetes, hyperlipemia, hypertension, cholelithiasis, arteriosclerosis, and cardiovascular and cerebrovascular disease (2). However, obesity was recently related to the aetiology and progression of periodontal disease. The first paper assessing this relationship was published in 1977, but the investigation was carried out on rats (3). It was not until 1998, that the first report on humans was published, establishing that obese Japanese subjects were 8.6 times more likely to suffer from periodontitis (4). Other studies followed, and many of them proved the association of body mass index (BMI) and/or upper body obesity with severity and prevalence of periodontal disease (5-11). Research led by Socransky and Haffajee at the Forsyth Institute also found increased proportions of Tannerella forsythia in extremely obese subjects, while obesity in general was related to deep pockets, attachment loss, bleeding on probing, and plaque accumulation (12). Nevertheless, in some studies the statistical significance of such findings was limited to younger adults, whereas in older population it was postulated that the possible association between obesity and periodontitis was annulled by co-morbidity and reduced number of teeth $(13,14)$.

Potential mechanisms behind the obesity-periodontitis relationship include the effect of obesity on immunity, obesity as a risk factor for hypertension, secretion of adipocytokines (including tumour necrosis factor- $\alpha$ ), secretion of plasminogen activator inhibitor-1, release of leptin from adipose tissue which acts on hypothalamic neurons, and finally elevated levels of CRP promoting hyperinflammatory state which may affect severity of periodontal disease in genetically susceptible individuals (15-17).

Regardless of these proposed, rather complex mechanisms, it is often speculated that one of the contributors to this relationship could also be the lack of health protective behaviour in overweight and obese persons, including oral health behaviours and general health habits $(18,19)$. Hujoel et al. found that absence of or lessened daily flossing correlates strongly to obesity in a dose-dependent manner, where the higher BMI meant lower likelihood for daily flossing (20). Other investigations of obesity and oral hygiene habits focused mainly on children and adolescents confirmed the finding that obesity was related to poor oral health (21-23). 
On the other hand, data on overweight/obesity and education level relationship are somewhat conflicting: it is obvious that, depending on population characteristics, overweight/obesity may be related to low income/low education level $(24,25)$ while in some cases it correlated inversely with education level $(26,27)$. This association between socio-economic status and obesity is mostly explained through so called "health-related behaviour", which varies largely in different populations. This problem is especially recognized in countries that recently joined the European Union (28).

Many researches have focused on how tooth loss (which could be attributable to periodontitis) is related to obesity, and dietary and nutrient intake. Johansson et al. found that edentulous men consumed fewer fruits and vegetables and had a lower intake of fibers, while edentulous women consumed higher amounts of fat. Both edentulous men and women ate more sweet snacks (29). The oral health survey of people participating in the British National Diet and Nutrition Survey (NDNS) found that the selection of foods was affected by the numbers of teeth and occluding pairs of teeth they had (30). Furthermore, recent investigation carried out in Southern Brazil found that edentulous subjects and the dentate with one to eight teeth were associated with obesity (31).

It is the position of the American Dietetic Association that nutrition is an integral component of oral health. Oral infectious diseases impact the functional ability to eat as well as diet and nutrition status (32). Therefore, the aim of our study was to investigate whether there were associations between obesity and periodontal status, oral hygiene and tooth loss in a homogenous group of Eastern European non-smoking, non-diabetic persons aged $31-60$ years.

\section{MATERIALS AND METHODS}

\section{Study Population}

This study has been designed as cross-sectional with convenient sampling. The subjects were consecutively recruited from patients who came to the Dental Clinic, Clinical Hospital Centre in Rijeka, Croatia, with a catchment area of three Croatian counties (including both urban and rural areas). Between September 2008 and January 2010, a total of 320 patients aged 31-75 years (median age 57 years) were recruited. Exclusion criteria applied were smoking (for previous smokers inclusion criterion was non-smoking status for at least 5 years), presence of neoplasms, autoimmune diseases, and chronic diseases known to be confounders for periodontitis (such as diabetes, renal and cardiovascular diseases). Full clinical oral examination (including periodontal examination) was completed for 292 subjects - the remainder of the sample included persons who were either edentulous or refused periodontal probing. Each participant was interviewed using a structured written questionnaire, with questions related to oral hygiene and education level. Measurements of weight and height were also recorded. Subjects who agreed to participate signed an informed consent form, and at the conclusion of the study were provided with reports of their oral status and significant findings.

\section{Obesity}

Body mass index (BMI) was used as an indicator of overweight/obesity; it was computed from weight in kilograms divided by square height in meters, and divided into four categories, according to WHO (1): underweight (BMI $\leq 18.5 \mathrm{~kg} / \mathrm{m}^{2}$ ), normal weight (BMI 18.5 to $24.9 \mathrm{~kg} / \mathrm{m}^{2}$ ), overweight (BMI 25 to $29.9 \mathrm{~kg}$ / $\mathrm{m}^{2}$ ), and obese $\left(\mathrm{BMI} \geq 30 \mathrm{~kg} / \mathrm{m}^{2}\right)$. Two subjects were classified as underweight and these were excluded from the study.

\section{Periodontal Status}

Clinical measurements were carried out by a single certified dental examiner on a dental chair using a manual periodontal probe (PCP10-SE, Hu-Friedy, Chicago, IL). Probing depth (PD) was defined as the distance from the free gingival margin to the bottom of the sulcus/pocket. Gingival recession was defined as the distance from the cemento-enamel junction (CEJ) to the free gingival margin (in cases where gingival margin was located coronal to the CEJ recession was assigned a negative sign). Clinical attachment loss (CAL) was calculated as the sum of probing depth and gingival recession. Clinical measurements were performed at mesial, distal, buccal, and palatal aspects of all permanent fully erupted teeth, excluding third molars. Measurements were made in millimetres and were rounded to the nearest whole millimetre; where any doubt existed the lower value was scored.

For the purpose of data analysis, three categories of periodontitis were defined (the American Dental Association, 1997): cases with attachment loss $\leq 4 \mathrm{~mm}$ and possible class I furcation invasion areas were considered as early periodontitis; cases with attachment loss 4-6 mm, grade I and/or grade II furcation invasion areas, and possible tooth mobility class I were categorized as moderate periodontitis; and finally cases with attachment loss $>6 \mathrm{~mm}$, grade II and/or grade III furcation invasion areas, and possible tooth mobility class II or class III were considered as advanced periodontitis.

Panoramic X-rays were taken only in cases where it was deemed necessary in order to confirm the diagnosis of periodontitis, in cases where certain teeth were marked as "problematic" due to carious lesions, presence of fistula or fracture, and finally in cases where the patients were referred for prosthetic rehabilitation.

\section{Oral Hygiene}

The following measures of oral hygiene maintenance were evaluated: frequency of tooth brushing, and use of interdental brushes and/or flossing.

The question related to tooth brushing was: "How many times a day do you typically brush your teeth?" The answers provided were: "none", "once a day", "twice a day", and "more than twice a day". Participants were also asked to describe the frequency of using means to maintain interdental hygiene (interdental brushes and flossing); the answers offered were: "every day", "occasionally" and "never".

\section{Education Level}

Since in the Republic of Croatia only elementary school education is obligatory, we categorized education level in the following manner: 1 - elementary school or no formal education; 2 - high 
school diploma; 3 - baccalaureate; and 4 - college/university graduate, Master of Science or PhD.

\section{Statistical Analysis}

Statistical analysis of data was performed using Statistica for Windows, release 8.1 (Stasoft, INC., Tulsa, OK, USA). The data of age and extraced teeth were presented as the mean \pm standard deviation (SD). For these results we used one-way analysis of variance (one-way ANOVA) to test the differences between groups according to category of BMI. The correlation analyses were expressed by the Pearson correlation coefficient or Spearman correlation coefficient, depending on the data. Associations between obesity and periodontitis, tooth loss and oral hygiene were adjusted for the demographic and socio-economic confounders by means of the multivariate logistic regression. All statistical values were considered significant at the p level of 0.05 .

\section{RESULTS}

In total, 292 subjects formed the basis for this investigation. There were 96 subjects (32.9\%) with normal weight (BMI $<25)$, $143(49 \%)$ subjects were overweight (BMI from 25 to 30), and $53(18.1 \%)$ obese subjects (BMI $>30)$. Statistical data regarding BMI category and periodontal disease, tooth brushing, use of interdental brushes/flossing, and a number of missing teeth are presented in Table 1.

The following investigated factors correlated significantly with BMI: use of interdental brushes/flossing and number of missing teeth. Obese persons were least likely to use interdental brushes/ flossing on a daily basis and had more missing teeth. Correlation between BMI and periodontal disease, and BMI and tooth brushing was not statistically significant. Correlation between the number of missing teeth and BMI is presented in Figure 1. The values of the Spearman rank coefficient of correlation between BMI and periodontal disease, tooth brushing, and use of interdental brushes/flossing are presented in Table 2.

Results of multivariate logistic regression analysis are presented in Table 3. It is obvious that in this investigated sample overweight and obese, poorly educated women aged 36-55 years were 5-6 times more likely to develop advanced forms of periodontal disease. When it came to oral hygiene habits, men who brushed less than once a day and women who never used interdental brushes/floss were exposed to greater risk.

\section{DISCUSSION}

The main findings of this study were that use of interdental brushes/flossing and a number of missing teeth were significantly associated with BMI, but this relationship could not be proven for periodontitis. However, when we performed multivariate logistic regression analysis, we found that the risk for developing periodontal disease significantly increased (OR 5.2-6.5) in female subjects, especially if they were poorly educated or had unsatisfactory oral hygiene habits. In addition, this analysis showed that the risk was limited to a particular age group (36-55 years of age). Therefore, we only partially corroborated the findings obtained by other investigators $(5-7,9,10,33,34)$.

One of the most important features of this study, which distinguishes it from the similar studies, was exclusion of diabetic and smoking subjects. Periodontitis was classified into three distinct categories, used in everyday practice to evaluate its severity and progression. Obese subjects $(\mathrm{BMI}>30)$ had the lowest prevalence of both moderate and severe periodontitis, and overweight subjects (BMI 25-30) had the highest prevalence of these two categories of periodontal disease. In addition, obese patients

Table 1. Baseline characteristics according to the category of BMI

\begin{tabular}{|c|c|c|c|c|}
\hline Factor & $\begin{array}{l}\text { Normal } \\
\text { BMI }<25\end{array}$ & $\begin{array}{l}\text { Overweight } \\
\text { BMI 25-30 }\end{array}$ & $\begin{array}{c}\text { Obese } \\
\text { BMI }>30\end{array}$ & Statistic \\
\hline \multicolumn{5}{|c|}{ Severity of periodontal disease, N (\%) } \\
\hline None & $11(22.4)$ & $9(12.5)$ & $7(26.9)$ & $x^{2}=1.44 ; p=0.485$ \\
\hline Early & $12(24.5)$ & $18(25)$ & $8(30.8)$ & $x^{2}=6.51 ; p=0.038^{*}$ \\
\hline Moderate & $17(34.7)$ & $21(29.2)$ & $6(23.1)$ & $x^{2}=14.94 ; p=0.006^{*}$ \\
\hline Advanced & $9(18.4)$ & $24(33.3)$ & $5(19.2)$ & $x^{2}=31.68 ; p<0.001^{*}$ \\
\hline \multicolumn{5}{|c|}{ Tooth brushing frequency, $\mathrm{N}(\%)$} \\
\hline Never & $1(2)$ & $1(1.4)$ & $0(0)$ & \\
\hline Once a day & $8(16.3)$ & $9(12.5)$ & $6(21.8)$ & $x^{2}=1.22 ; p=0.544$ \\
\hline Twice a day & $26(53.1)$ & $41(56.9)$ & $13(45.5)$ & $x^{2}=30.1 ; p=0.001^{*}$ \\
\hline More than twice a day & $14(28.6)$ & $21(29.2)$ & $9(32.7)$ & $x^{2}=9.37 ; p=0.009^{*}$ \\
\hline \multicolumn{5}{|c|}{ Interdental brushes/flossing frequency, N (\%) } \\
\hline Daily & $6(12.2)$ & $6(8.3)$ & $2(7.7)$ & $x^{2}=5.62 ; p=0.060$ \\
\hline Occasionally & $12(24.5)$ & $11(15.3)$ & $3(11.5)$ & $x^{2}=8.00 ; p=0.018^{*}$ \\
\hline Never & $31(63.3)$ & $55(76.4)$ & $21(80.8)$ & $X^{2}=31.42 ; p=0.001^{*}$ \\
\hline \multicolumn{5}{|c|}{ Number of missing teeth, Mean \pm SD } \\
\hline & $12.7 \pm 9.7$ & $14.5 \pm 8.3$ & $16.1 \pm 9.5$ & $F=2.50 ; p=0.084$ \\
\hline
\end{tabular}

*Indicated significant difference between the groups according to category of BMI. 
Table 2. The values of Spearman rank coefficient of correlation between examined factors and BMI

\begin{tabular}{|l|c|c|}
\hline & BMI & Statistic $\mathbf{P}$ \\
\hline Severity of periodontal disease & 0.005 & 0.605 \\
\hline Tooth brushing & 0.013 & 0.883 \\
\hline Use of interdental brushes/flossing & 0.146 & 0.003 \\
\hline
\end{tabular}

were most likely to be periodontally healthy, but the differences between the mentioned groups were not statistically significant. Nevertheless, logistic regression analysis showed that BMI correlated with development of periodontitis in a specific subset of population comprised of female patients aged 36-55 years who were poorly educated and failed to floss regularly (OR 5.2-6.5). Other investigators who addressed this association $(5-7,9,10$, 33,34 ) found many variations in strength of periodontitis-obesity relationship; furthermore, some of these studies proved - similarly to our study - that this relationship was significant only in younger age groups $(13,14)$ or in female patients $(9)$. Although scarce, there are studies which failed to prove the positive relationship between periodontitis and obesity - in this context we have to mention a study recently performed in Denmark which proved that BMI may actually be inversely associated with clinical attachment loss, but positively associated with bleeding on probing (35).

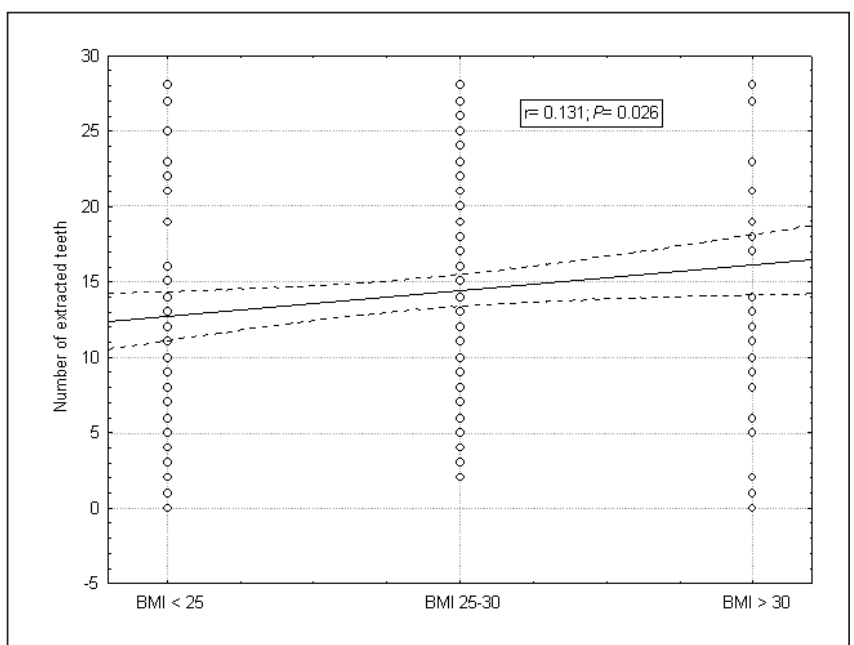

Fig. 1. Association of obesity with periodontitis.

Correlation between the number of missing teeth and category of BMI. Number of missing teeth was significantly correlated to the category of BMI $(p=0.026)$.

The above mentioned variations in strength may be due to different cut offs used to identify periodontal disease. For example, Saito et al. (5) used probing depth of $\geq 3.5 \mathrm{~mm}$; consequently, over $50 \%$ of the subjects had periodontal disease. Dalla Vecchia et al. (9) considered individuals to have periodontal disease if they had $\geq 30 \%$ of their teeth with attachment loss $\geq 5 \mathrm{~mm}$, and

Table 3. Effect of body mass index, age, toothbrushing, use of interdental brushes/floss and level of education on occurrence of periodontitis

\begin{tabular}{|c|c|c|c|c|c|c|}
\hline \multirow{3}{*}{ Independent variables } & \multicolumn{6}{|c|}{ Gender } \\
\hline & \multicolumn{3}{|c|}{ Males $(n=42)$} & \multicolumn{3}{|c|}{ Females ( $n=107)$} \\
\hline & OR & $95 \% \mathrm{Cl}$ & $\mathrm{p}$ & OR & $95 \% \mathrm{Cl}$ & $p$ \\
\hline \multicolumn{7}{|l|}{ BMI } \\
\hline Normal & 0.4 & $0.0-5.1$ & 0.448 & 0.8 & $0.2-3.3$ & 0.760 \\
\hline Overweight & 5.0 & $0.6-44.1$ & 0.151 & 5.2 & $1.1-25.6$ & $0.044^{*}$ \\
\hline Obese & 2.8 & $0.4-19.6$ & 0.286 & 6.5 & $1.9-22.5$ & $0.003^{*}$ \\
\hline \multicolumn{7}{|l|}{ Age } \\
\hline $25-35$ & 0.7 & $0.0-41.2$ & 0.861 & 0.6 & $0.0-18.8$ & 0.789 \\
\hline $36-55$ & 3.4 & $0.7-16.7$ & 0.131 & 8.3 & $1.9-36.4$ & $0.006^{*}$ \\
\hline 56 and more & 1.0 & $0.4-2.4$ & 0.958 & 2.1 & $0.9-4.9$ & 0.084 \\
\hline \multicolumn{7}{|l|}{ Toothbrushing frequency } \\
\hline$<$ once a day & 9.0 & $0.5-128.1$ & $0.006^{*}$ & 5.0 & $0.2-128$ & 0.321 \\
\hline once a day & 2.2 & $0.4-13.2$ & 0.149 & 4.4 & $1.5-12.7$ & 0.379 \\
\hline$\geq 2$ times a day & 0.9 & $0.1-6.9$ & 0.971 & 1.6 & $0.5-5.1$ & 0.426 \\
\hline \multicolumn{7}{|l|}{ Interdental brushes/floss } \\
\hline Every day & 1.9 & $0.0-115.0$ & 0.768 & 0.5 & $0.2-15.3$ & 0.717 \\
\hline Occasionally & 1.6 & $0.5-4.9$ & 0.717 & 0.8 & $0.1-21.1$ & 0.892 \\
\hline Never & 2.1 & $0.0-132.0$ & 0.456 & 3.2 & $1.4-7.2$ & $0.007^{*}$ \\
\hline \multicolumn{7}{|l|}{ Level of education } \\
\hline 1 & 7.3 & $0.2-226$ & 0.103 & 12.3 & $0.5-291$ & $0.022^{*}$ \\
\hline 2 & 7.4 & $0.8-63.5$ & 0.069 & 1.8 & $0.6-4.9$ & 0.285 \\
\hline 3 & 1.7 & $0.1-47.8$ & 0.766 & 1.5 & $0.0-81.6$ & 0.581 \\
\hline 4 & 0.1 & $0.0-1.5$ & 0.257 & 4.5 & $1.2-16.7$ & 0.129 \\
\hline
\end{tabular}

*Indicated statistical significance 
consequently found that $50.7 \%$ of males and $35.3 \%$ of females were affected by periodontitis. Studies utilizing NHANES III data defined periodontal disease based on the presence of one or more periodontal sites with both attachment loss of $\geq 3 \mathrm{~mm}$ and probing depth of $\geq 4 \mathrm{~mm}(6,13)$, and prevalence of periodontitis was as low as $14 \%$ in the total population. In our study, prevalence of early periodontitis was $27.8 \%$. More importantly, moderate periodontitis was found in $28.6 \%$ of the subjects and advanced periodontitis was detected in $23.6 \%$ of the examined subjects. These findings can only be compared to the ones obtained by Ivić-Kardum where old classification of periodontal diseases was used and $47.7 \%$ of the subjects examined had "adult periodontitis" (presently termed chronic periodontitis) (36).

Obese subjects in our age group (31-75 years) flossed/used interdental brushes less. Although self-reported oral hygiene habits are not absolutely reliable markers of plaque absence, flossing and use of interdental brushes were considered as important indicators of oral hygiene maintenance in relation to tooth brushing, since only people who clean their interdental spaces regularly can achieve good levels of oral hygiene. Hujoel et al. in their longitudinal cohort study of 1,497 individuals from the Western United States found that absence of or lessened daily flossing correlates strongly to obesity in a dose-dependent manner, where the higher BMI meant lower likelihood for daily flossing (20). Linden et al. also found that Northern Irish people aged 60-70 years who were obese had poorer oral hygiene (10). Flossing and/ or use of interdental brushes reflect both oral and general health awareness. Good oral health could be related to positive general health awareness, where persons who care for their general health observe tedious daily oral hygiene routines. This general health awareness might also be reflected through the absence of obesity. However, there are other biological mechanisms which could explain the interdental hygiene-obesity association. Lack of flossing is associated with anaerobic interproximal conditions, which may create reservoirs for Helicobacter pylori. These bacteria may promote the release of ghrelin from gastric A-like cells, which acts as a potent appetite stimulator (37). Another explanation is that release of interproximal food between the meals might stimulate taste receptors and promote feeding (20). Regardless of the results of this and future studies addressing this issue, it becomes obvious that prevention of both oral and systemic diseases should include not only general health awareness factors, but also measures to improve oral health.

It is obvious that oral disease epidemiology is very complex, and these findings give us only a minor insight into how the overall oral health is modelled. Tooth loss, obviously leads to changes in nutrition since eating a variety of food stuffs is clearly influenced by the number of teeth present (30), and impaired dentition may contribute to weight change, depending on age and population characteristics (38). In free-living population of older people this usually means increased BMI, which was also proved in our investigation. Hilgert et al. proved that in older Brazilian people ( $>60$ years) edentulousness and dentition with 1-8 teeth were significantly associated with obesity (31). In a controlled Swedish population, the investigators found a significant relationship between age and tooth loss, but only in those aged 30-60 years (39). However, there are reports that tooth loss is associated with BMI less than $21 \mathrm{~kg} / \mathrm{m} 2$, but only in nursing home residents (40). It is important to note that co-morbidity and socio-economic status may confound the nutrition-oral health association. Since the absence of longitudinal studies in large populations it is difficult to establish whether oral conditions precede or follow weight change.

The subjects included in this investigation were exclusively of Eastern European origin. To our knowledge, there are no other studies on subjects from this region regarding the possible relationship between BMI and oral health. Obese persons in our age group (31-75 years) with lower education levels had worse oral health, flossed/used interdental brushes less and had more missing teeth. One of the major drawbacks of this study was rather high median age (57 years) - possible impact of obesity on periodontal status might be more pronounced in younger age groups where there are less co-morbidities. Another drawback was the study design: this was a cross-sectional study which did not allow us to gain an insight into progression of oral health - BMI relationship over time.

It is still arguable whether there is a direct causal relationship between oral health, especially periodontitis, and obesity. If the association exists, the question is whether obesity predispose a person to development of periodontitis due to its effect on inflammatory and immune systems, or is it the other way around - bad oral hygiene habits, lack of teeth, and periodontitis favour weight gain? The role fat cells play in the regulation of inflammation and immunity has labelled obesity as a chronic disease (41). The systemic inflammation associated with obesity may affect susceptibility to chronic infectious diseases such as periodontitis. Furthermore, it has been shown that adipose tissue (adipocytes) secretes several proinflammatory factors, also implicated in periodontitis including cytokines (e.g. IL-6), chemokines and can affect T-cell function (42-44). Such interrelationship in a particular age group (as proved in this investigation) may be the consequence of continuous exposure; in older age groups it is lost due to co-morbidity and possibly reduced number of teeth.

From a public health aspect, data from this investigation may be useful in designing a Croatian obesity prevention programme; furthermore, future investigations should be prospective longitudinal studies in non-smoking, non-diabetic subjects (since these are major confounding factors for periodontitis), with similar health awareness and with strictly controlled measures of periodontal disease and obesity. Since BMI is not a gold standard measure of obesity, measures of obesity should include not only BMI but also waist circumference and muscle fitness. Nevertheless, patients should be advised by their general practitioners, medical specialists and dentists alike to modify their health behaviours, both general and oral, in order to improve their quality of life and reduce possible negative effects of oral disease-systemic disease associations.

\section{Acknowledgement}

The authors acknowledge the assistance of the nurses at the Dental Clinic, Clinical Hospital Centre in Rijeka, Croatia who helped with the entire paperwork and contacts with investigated subjects.

\section{Conflict of Interest}

None declared

\section{Sponsorship}

The research has been supported by the Ministry of Science, Education and Sport of the Republic of Croatia. 


\section{Adherence to Ethical Recommendations}

The study protocol was independently reviewed and approved by the Research Ethics Committee of the Medical Faculty, University of Rijeka and the research has been conducted in full accordance with ethical principles including the World Medical Association Declaration of Helsinki (version VI, 2002).

\section{REFERENCES}

1. Obesity: preventing and managing the global epidemic. Report of a WHO consultation. World Health Organ Tech Rep Ser. 2000;894:i-xii, 1-253.

2. Kopelman PG. Obesity as a medical problem. Nature. $2000 \mathrm{Apr}$ 6;404(6778):635-43.

3. Perlstein MI, Bissada NF. Influence of obesity and hypertension on the severity of periodontitis in rats. Oral Surg Oral Med Oral Pathol. 1977 May;43(5):707-19.

4. Saito T, Shimazaki Y, Sakamoto M. Obesity and periodontitis. N Engl J Med. 1998 Aug 13;339(7):482-3.

5. Saito T, Shimazaki Y, Koga T, Tsuzuki M, Ohshima A. Relationship between upper body obesity and periodontitis. J Dent Res. 2001 Jul;80(7):1631-6.

6. Wood N, Johnson RB, Streckfus CF. Comparison of body composition and periodontal disease using nutritional assessment techniques: Third National Health and Nutrition Examination Survey (NHANES III). J Clin Periodontol. 2003 Apr;30(4):321-7.

7. Nishida N, Tanaka M, Hayashi N, Nagata H, Takeshita T, Nakayama $\mathrm{K}$, et al. Determination of smoking and obesity as periodontitis risks using the classification and regression tree method. J Periodontol. 2005 Jun;76(6):923-8.

8. Saito T, Shimazaki Y, Kiyohara Y, Kato I, Kubo M, Iida M, et al. Relationship between obesity, glucose tolerance, and periodontal disease in Japanese women: the Hisayama study. J Periodontal Res. 2005 Aug;40(4):346-53.

9. Dalla Vecchia CF, Susin C, Rösing CK, Oppermann RV, Albandar JM. Overweight and obesity as risk indicators for periodontitis in adults. J Periodontol. 2005 Oct; 76(10):1721-8.

10. Linden G, Patterson C, Evans A, Kee F. Obesity and periodontitis in 60-70-year-old men. J Clin Periodontol. 2007 Jun;34(6):461-6.

11. Han DH, Lim SY, Sun BC, Paek DM, Kim HD. Visceral fat area-defined obesity and periodontitis among Koreans. J Clin Periodontol. 2010 Feb;37(2):172-9.

12. Socransky SS, Haffajee AD. Periodontal microbial ecology. Periodontol 2000. 2005;38:135-87.

13. Al-Zahrani MS, Bissada NF, Borawskit EA. Obesity and periodontal disease in young, middle-aged, and older adults. J Periodontol. 2003 May;74(5):610-5.

14. Alabdulkarim M, Bissada N, Al-Zahrani M, Ficara A, Siegel B. Alveolar bone loss in obese subjects. J Int Acad Periodontol. 2005 Apr;7(2):34-8

15. Saito T, Shimazaki Y. Metabolic disorders related to obesity and periodontal disease. Periodontol 2000. 2007;43:254-66.

16. Kornman KS. Mapping the pathogenesis of periodontitis: a new look. J Periodontol. 2008 Aug;79(8 Suppl):1560-8.

17. Tintera J, Harantová P, Suchánek P, Dvoráková A, Adamová M, Hájek $\mathrm{M}$, et al. Quantification of intra-abdominal fat during controlled weight reduction: assessment using the water-suppressed breath-hold MRI technique. Physiol Res. 2004;53(2):229-34.

18. Doll HA, Petersen SE, Stewart-Brown SL. Obesity and physical and emotional well-being: associations between body mass index, chronic illness, and the physical and mental components of the SF-36 questionnaire. Obes Res. 2000 Mar;8(2):160-70.

19. Hassan MK, Joshi AV, Madhavan SS, Amonkar MM. Obesity and healthrelated quality of life: a cross-sectional analysis of the US population. Int J Obes Relat Metab Disord. 2003 Oct;27(10):1227-32.

20. Hujoel PP, Cunha-Cruz J, Kressin NR. Spurious associations in oral epidemiological research: the case of dental flossing and obesity. J Clin Periodontol. 2006 Aug;33(8):520-3.

21. Willershausen B, Haas G, Krummenauer F, Hohenfellner K. Relationship between high weight and caries frequency in German elementary school children. Eur J Med Res. 2004 Aug 31;9(8):400-4.

22. Cinar AB, Murtomaa H. Interrelation between obesity, oral health and life-style factors among Turkish school children. Clin Oral Investig. 2011 Apr;15(2):177-84.
23. Franchini R, Petri A, Migliario M, Rimondini L. Poor oral hygiene and gingivitis are associated with obesity and overweight status in paediatric subjects. J Clin Periodontol. 2011 Nov;38(11):1021-8.

24. Milanović SM, Uhernik AI, Fister K, Mihel S, Kovac A, Ivanković D. Five-year cumulative incidence of obesity in adults in Croatia: the CroHort study. Coll Antropol. 2012 Jan;36 Suppl 1:71-6.

25. Aguilera A, Leykin Y, Adler N, Muñoz RF. Assessing the impact of relative social position and absolute community resources on depression and obesity among smokers. Am J Community Psychol. 2012 Sep;50(12):211-6.

26. Ahmed F, Waslien C, Al-Sumaie MA, Prakash P. Secular trends and risk factors of overweight and obesity among Kuwaiti adults: National Nutrition Surveillance System data from 1998 to 2009. Public Health Nutr. 2012 Nov;15(11):2124-30.

27. Wronka I, Suliga E, Pawlińska-Chmara R. Socioeconomic determinants of underweight and overweight in female Polish students in 2009. Anthropol Anz. 2012;69(1):85-96.

28. Nédó E, Paulik E. Association of smoking, physical activity, and dietary habits with socioeconomic variables: a cross-sectional study in adults on both sides of the Hungarian-Romanian border. BMC Public Health. 2012 Jan 20;12:60.

29. Ritchie CS, Joshipura K, Hung HC, Douglass CW. Nutrition as a mediator in the relation between oral and systemic disease: associations between specific measures of adult oral health and nutrition outcomes. Crit Rev Oral Biol Med. 2002;13(3):291-300.

30. Sheiham A, Steele JG, Marcenes W, Finch S, Walls AWG. The impact of oral health on stated ability to eat certain foods; findings from the National Diet and Nutrition Survey of Older People in Great Britain. Gerodontology. 1999 Jul;16(1):11-20.

31. Hilgert JB, Hugo FN, Sousa MdLRd, Bozzetti MC. Oral status and its association with obesity in Southern Brazilian older people. Gerodontology. 2009 Mar;26(1):46-52.

32. Touger-Decker R, Mobley CC; American Dietetic Association. Position of the American Dietetic Association: oral health and nutrition. J Am Diet Assoc. 2007 Aug;107(8):1418-28.

33. Salekzamani Y, Shirmohammadi A, Rahbar M, Shakouri SK, Nayebi F Association between Human Body Composition and Periodontal Disease. ISRN Dent. 2011;2011:863847.

34. Mathur LK, Manohar B, Shankarapillai R, Pandya D. Obesity and periodontitis: a clinical study. J Indian Soc Periodontol. 2011 Jul;15(3):240-4.

35. Kongstad J, Hvidtfeldt UA, Grønbaek M, Stoltze K, Holmstrup P. The relationship between body mass index and periodontitis in the Copenhagen City Heart Study. J Periodontol. 2009 Aug;80(8):1246-53.

36. Ivić-Kardum M. Prevalence of progressive periodontal disease in the population of Zagreb. Acta Stomatol Croat. 2000;34(2):157-61.

37. Isomoto H, Ueno H, Nishi Y, Wen CY, Nakazato M, Kohno S. Impact of Helicobacter pylori infection on ghrelin and various neuroendocrine hormones in plasma. World J Gastroenterol. 2005 Mar 21;11(11):1644-8.

38. Ritchie CS, Joshipura K, Hung HC, Douglass CW. Nutrition as a mediator in the relation between oral and systemic disease: associations between specific measures of adult oral health and nutrition outcomes. Crit Rev Oral Biol Med. 2002;13(3):291-300.

39. Ostberg AL, Nyholm M, Gullberg B, Råstam L, Lindblad U. Tooth loss and obesity in a defined Swedish population. Scand J Public Health. 2009 Jun;37(4):427-33.

40. Mojon P, Budtz-Jørgensen E, Rapin CH. Relationship between oral health and nutrition in very old people. Age Ageing. 1999 Sep;28(5):463-8.

41. Bray GA. Obesity is a chronic, relapsing neurochemical disease. Int J Obes Relat Metab Disord. 2004 Jan;28(1):34-8.

42. Falagas ME, Kompoti M. Obesity and infection. Lancet Infect Dis. 2006 Jul;6(7):438-46.

43. Boesing F, Patiño JSR, da Silva VRG, Moreira EAM. The interface between obesity and periodontitis with emphasis on oxidative stress and inflammatory response. Obes Rev. 2009 May;10(3):290-7.

44. Lundin M, Yucel-Lindberg T, Dahllöf G, Marcus C, Modéer T. Correlation between TNFalpha in gingival crevicular fluid and body mass index in obese subjects. Acta Odontol Scand. 2004 Oct;62(5):273-7. 